\title{
N-3 Fatty Acid Deficiency Induced by a Modified Artificial Rearing Method Leads to Poorer Performance in Spatial Learning Tasks
}

\author{
SUN-YOUNG LIM, JUNJI HOSHIBA, TORU MORIGUCHI, AND NORMAN SALEM, JR. \\ Marine Environment and Bioscience [S.-Y.L.], Korea Maritime University, 606-791, Busan, Korea; \\ Department of Animal Resources [J.H.], Advanced Science Research Center, Okayama University, \\ Okayama, 700-8558, Japan; Laboratory of Membrane Biochemistry and Biophysics [T.M., N.S.], National \\ Institute on Alcohol Abuse and Alcoholism, National Institutes of Health, Bethesda, Maryland 20892-9410
}

\section{ABSTRACT}

Docosahexaenoic acid (DHA) is a major structural component of the nervous system, and depletion may lead to losses in neural function. Our objective was to demonstrate a deficit in spatial task performance in rats with low brain DHA due to a low n-3 fatty acid intake using a first-generational artificial rearing technique. Newborn rat pups were separated on $\mathrm{d} 2$ and assigned to two artificial rearing groups or a dam-reared control group. Pups were hand fed artificial milk via custom-designed nursing bottles containing either $0.02 \%$ (n-3 Def) or $3.1 \%$ (n-3 Adq) of total fatty acids as LNA. At d 21, rats were weaned to either n-3 Def or n-3 Adq pelleted diets and several behavioral tasks were evaluated at 9 wk of age. Brain DHA was lower (58\% and $61 \%$, $p<0.001)$ in n-3 Def in comparison to n-3 Adq and dam-reared rats, respectively. At adulthood, the n-3 fatty acid-deficient rats had a significantly greater moving time than the dam-reared group $(p<0.05)$, but there were no differences among the three groups in the elevated plus maze test. The $n-3$ fatty acid deficient rats exhibited a longer escape latency $(p<0.05)$ and poorer memory retention in the Morris water maze compared with n-3 fatty acid adequate and dam-reared rats. We concluded that artificial rearing can be used to produce $n-3$ fatty acid deficiency in the first generation. This deficiency was associated with significantly reduced spatial learning. Adequate brain DHA levels are required for optimal spatial learning. (Pediatr Res 58: 741-748, 2005)
AA, arachidonic acid
Abbreviations
$\mathbf{A R}$, artificial rearing
DHA, docosahexaenoic acid, 22:6n-3
DPAn-6, docosapentaenoic acid, n-6, 22:5n-6
EPA, eicosapentaenoic acid
LA, linoleic acid
LNA, alpha-linolenic acid, 18:3n-3
n-3 Adq, n-3 fatty acid adequate group
n-3 Def, n-3 fatty acid deficient group

Many studies have now demonstrated that prolonged consumption of an n-3 fatty acid-deficient diet resulted in a loss in brain and retinal DHA leading to losses in neural function (1-5). For example, the decrease in brain DHA was associated with poorer performance on simple associative learning tasks (6-8), alterations in electroretinograms (9-13), and spatial task performance in rodents (14-16). Our previous work showed that rats on an n-3 fatty acid deficient diet throughout two generations had a defect in two-odor olfactory discrimination tasks $(17,18)$ and olfactory-cued set learning (19). In these studies, brain DHA decreased by $83 \%$ with compensation by an increase in brain DPAn-6. Rhesus monkey infants fed n-3 fatty acid-deficient diets had increased look duration (20)

Received January 6, 2005; accepted February 11, 2005.

Correspondence: Norman Salem, Jr., Ph.D., 5625 Fishers Ln., Room 3N-07, NIAAA, NIH, Bethesda, MD 20892-9410; e-mail: nsalem@niaaa.nih.gov

DOI: 10.1203/01.PDR.0000180547.46725.CC whereas monkeys supplemented with $1 \%$ DHA and 1\% AA during early development exhibited stronger orienting and motor skills (21).

The general paradigm used in these studies was a twogeneration model in which dams are fed a diet nearly devoid of sources of n-3 fatty acids and their offspring studied while maintained on the n-3 fatty acid deficient diet. This has proven to be a most useful approach to induce the loss of brain and retinal DHA and enable study of functional losses. It was remarkable that the diet-induced substitution of the 22-carbon n-6 polyunsaturate DPAn-6 for neural DHA was associated with these losses in brain and retinal function. Studies of subsequent DHA repletion has shown in a fairly conclusive manner that the functional gain was indeed related to the increase in DHA and the decline in DPAn-6. In particular, when function returns together with brain or retinal DHA in a repletion experiment, this was strong evidence that the gain in function was indeed due to the gain in neural DHA (22-24), 
although there has been one suggestion that not only the levels of DHA but also that of AA must normalize to restore proper brain function (25). Kodas et al. (26) found that altered dopaminergic neurotransmission induced by chronic $n-3$ fatty acid deficiency was reversed with supply of an LNA diet when provided from birth or during the first $2 \mathrm{wk}$ of life, suggesting that critical periods exist for $\mathrm{n}-3$ fatty acid supply for neural development.

One limitation of the two-generational deficiency approach is that it poorly mimics the human situation. Although the intake of the longer chain n-3 fatty acids, EPA and DHA are quite low in the western world, particularly in North America (27), where there is a mean intake of the n-3 precursor LNA of about $1.5 \mathrm{~g} / \mathrm{d}(28-30)$. This is reflected in circulating pools of $\mathrm{n}-3$ fatty acids as, for example, the percentage of serum total n-3 fatty acids in Americans was only $2.5 \%$ whereas the percentage in Japanese was 9-11.8\% (31). These low levels are the result of the low intake of preformed EPA and DHA together with the low rate of metabolic conversion of LNA to EPA and DHA in vivo (32). Nevertheless, a moderate level of n-3 fatty acid intake is able to support, to some extent, brain and retinal DHA $(33,34)$ as it appears to be accreted against a concentration gradient. This is not to say that the brain levels in the case of low n-3 fatty acid intake are the same as those with higher levels of intake of preformed DHA $(33,35,36)$, an observation that may have relevance to the growing psychiatric literature that associates n-3 fatty acid intake with the propensity toward the development of various psychiatric ailments (37-39).

For many animal studies, a significant decrease in brain DHA is required to produce a measurable decline in organ or organism function (22). More specifically, it appears that a $50 \%$ or greater loss of DHA may be required to observe such differences $(22,40)$. Thus, a model of n-3 fatty acid deficiency that better mimics the human situation but that still produces a substantial decline in brain and retinal DHA would be very valuable for the development of this field.

Recently, efforts have been made in our laboratory $(41,42)$ to develop a first-generation model of n-3 fatty acid deficiency using an artificial rearing approach pioneered by Hoshiba $(43,44)$. This method employs a feeding rack containing six silicon nipples from which the animals can be taught to feed. However, in our hands, pup survival was poor due to difficulties with the adjustment of the nipple resistance, which was critical for a proper flow rate upon pup suckling. Hoshiba has improved upon this method with the introduction of a new type of nursing bottle for hand feeding that leads to much better pup survival (45). These methods are unique in that they allow for the artificial rearing (AR) of rat pups from around the first day of life. The hand-feeding technique with the newly developed bottles was thus used for the present work.

In this experiment, the dams were fed a diet containing 3 wt $\%$ LNA, an "n-3 adequate" diet. Their pups were fed artificial rat milk beginning on the second day of life. In this manner, total control of the nutrient and essential fatty acid intake, in particular, was obtained. Artificial rat milk diets were formulated after the method of Kanno et al. (46) but were modified so as to provide very low levels of $\mathrm{n}-3$ fatty acids, or a diet incorporating $3 \mathrm{wt} \%$ LNA. The loss in brain DHA associated with an $\mathrm{n}-3$ fatty acid deficient diet and the performance of pups on several behavioral tasks were characterized. Measures of locomotor activity and activity on the elevated plus maze were made as controls for the key endpoint of spatial task performance in the Morris water maze. Spatial task performance consisted of measures of escape latency over a 4-d period, as previously established for a two-generation model of n-3 fatty acid deficiency, as well as a probe trial in which the platform was removed in the swim test $(16,22)$. Our hypothesis was that feeding the n-3 fatty acid deficient diet from shortly after birth through adulthood would lead to a marked decrease in brain DHA and that this would result in losses in spatial task performance.

\section{MATERIALS AND METHODS}

Animals and study design. This experimental protocol was approved by the Animal Care and Use Committee of the National Institute on Alcohol Abuse and Alcoholism, National Institutes of Health. Time-pregnant, female LongEvans rats on $\mathrm{d} 3$ of gestation were obtained from Charles River (Portage, MI) and immediately started on an " $\mathrm{n}-3$ adequate" pelleted diet (maternal diet) containing 3.1\% $\alpha$-linolenic acid (Table 1). They were maintained in our animal facility under conventional conditions with controlled temperature (23 $\left.\pm 1^{\circ} \mathrm{C}\right)$ and illumination $(12 \mathrm{~h}, 0600-1800 \mathrm{~h})$ and water was provided $a d$ libitum. At postnatal d 2, three male pups were selected from each litter $(n=$ 12 litters) based upon body weight and age so that they were born within a 12-h time window and a similar group mean body weight. They were then randomly allocated into each of the three groups. In this manner, each of the groups was

Table 1. Nutrient and fatty acid composition of pelleted diets given to dams and pups at weaning

\begin{tabular}{|c|c|c|c|}
\hline Ingredient & \multicolumn{3}{|c|}{ Amount $(\mathrm{g} / 100 \mathrm{~g})$} \\
\hline Casein, Vitamin free* & \multicolumn{3}{|c|}{20} \\
\hline \multicolumn{4}{|l|}{ Carbohydrates: } \\
\hline Corn starch & \multicolumn{3}{|c|}{15} \\
\hline Sucrose & \multicolumn{3}{|c|}{10} \\
\hline Dextrose & \multicolumn{3}{|c|}{19.9} \\
\hline Maltose-dextrin & \multicolumn{3}{|c|}{15} \\
\hline Cellulose & \multicolumn{3}{|c|}{5} \\
\hline Mineral and salt mix $\dagger$ & \multicolumn{3}{|c|}{3.5} \\
\hline Vitamin mix $\ddagger$ & \multicolumn{3}{|c|}{1} \\
\hline L-Cystine & \multicolumn{3}{|c|}{0.3} \\
\hline Choline bitartrate & \multicolumn{3}{|c|}{0.25} \\
\hline TBHQ§ & \multicolumn{3}{|c|}{0.002} \\
\hline Fat: & Maternal & n-3 Def & n-3 Adq \\
\hline Hydrogenated coconut oil & 7.75 & 2.7 & 2.7 \\
\hline Safflower oil & 1.77 & - & - \\
\hline Flaxseed oil & 0.48 & - & - \\
\hline Medium chain triglyceride & - & 1.3 & 1.3 \\
\hline $18: 1 n-9$ ethyl ester & - & 4.5 & 4.2 \\
\hline $18: 2 n-6$ ethyl ester & - & 1.5 & 1.5 \\
\hline $18: 3 n-3$ ethyl ester & - & - & 0.3 \\
\hline \multicolumn{4}{|l|}{ Fatty acid composition (wt \%) } \\
\hline Total Saturated & 77.2 & 28.0 & 29.2 \\
\hline Total monounsaturated & 4.3 & 52.2 & 48.2 \\
\hline $18: 2 n-6$ & 15.3 & 17.8 & 17.6 \\
\hline $18: 3 n-3$ & 3.1 & 0.06 & 3.2 \\
\hline$n-6 / n-3$ & 4.9 & 296.7 & 5.5 \\
\hline
\end{tabular}

* Dyets Inc. catalogue \#400625 for maternal diet and ALACID casein (NZMP North America Inc) for n-3 Def and n-3 Adq diet.

$\dagger$ Dyets Inc. catalogue \#210025.

\$ Dyets Inc. catalogue \#310025.

$\S$ TBHQ is tert-butyl hydroquinone. 
composed of 12 male pups from each of the 12 different dams and each dietary group was composed of siblings of individuals in the other groups. The first group was the control group and was allowed to suckle from dams fed on an n-3 fatty acid adequate diet (dam's milk group). The second and third groups were artificially fed one of the two experimental milks (n-3 fatty acid deficient milk and n-3 fatty acid adequate milk group, respectively, Table 2).

Artificial rearing system. The artificial rearing procedure used was the hand-feeding technique with newly developed nursing bottles as described by Hoshiba (45). The artificial rearing system consisted of a custom made nursing bottle, cage, stainless steel sieve, cover lid, and electronic hot pad. The nursing bottles, custom made by Dr Junji Hoshiba, were composed of nipples, a milk inflow tube, a milk overflow tube, and a refill syringe (Fig. 1). The cage was placed on an electronically thermostated hot pad initially set at $33.5^{\circ} \mathrm{C}$. The temperature was slowly decreased over the next several days until it was $30^{\circ} \mathrm{C}$ by $\mathrm{d} 6$, where it remained until d 15 ; the pad was then maintained at $28^{\circ} \mathrm{C}$ until d 21. A stainless steel sieve was placed on the top of the cage with some chopped up paper towels for bedding. Fresh artificial milk was loading into the nursing bottle by a refill syringe. There were separate cages for each of the two dietary groups with one receiving the n-3 fatty acid-deficient milk and the other the n-3 fatty acid-adequate milk. On postnatal d 2, pups were capable of suckling from silicon nipples connected to the nursing bottles. They were separated from their dams and fed artificial milk from a nursing bottle with a silicon nipple every $3 \mathrm{~h}$ by hand for a total of $13 \mathrm{~h}$ per day. The nursing bottles with silicon nipples and fresh milk were kept in a refrigerator after feeding to minimize bacterial growth. The hand feeding was performed until postnatal 14-15 when they opened the eyes. Milk was then provided twice per day in 40

Table 2. Nutrient composition of artificial rat milk diets

\begin{tabular}{|c|c|}
\hline Ingredient & Amount (mg/100 ml milk) \\
\hline Casein (ALACID, acid casein)* & 6275 \\
\hline Whey protein isolate (ALACEN895)* & 4000 \\
\hline Carbohydrate (alpha-lactose) $\dagger$ & 1893 \\
\hline Serine $\dagger$ & 28.8 \\
\hline Cystine $\dagger$ & 22.5 \\
\hline Tryptophan $\dagger$ & 27.0 \\
\hline \multicolumn{2}{|l|}{ Minerals: } \\
\hline $\mathrm{NaOH} \dagger$ & 2100 \\
\hline $\mathrm{KOH}^{\dagger}$ & 170 \\
\hline $\mathrm{GlyCaPO}_{4} \dagger$ & 800 \\
\hline $\mathrm{MgCl}_{2} 6 \mathrm{H}_{2} \mathrm{O}$ & 183 \\
\hline $\mathrm{CaCl}_{2} 2 \mathrm{H}_{2} \mathrm{O}+$ & 210 \\
\hline $\mathrm{Ca}_{3} 4 \mathrm{H}_{2} \mathrm{O}$-Citrate $\dagger$ & 250 \\
\hline $\mathrm{Na}_{2} \mathrm{HPO}_{4}+$ & 114 \\
\hline $\mathrm{KH}_{2} \mathrm{PO}_{4}^{+}+$ & 51.0 \\
\hline $\mathrm{FeSO}_{4} \dagger$ & 3.0 \\
\hline $\mathrm{ZnSO}_{4} \dagger$ & 6.0 \\
\hline $\mathrm{CuSO}_{4}^{\dagger}$ & 1.6 \\
\hline $\mathrm{MnSO}_{4} \dagger$ & 0.07 \\
\hline $\mathrm{NaF} \dagger$ & 0.16 \\
\hline $\mathrm{KI} \dagger$ & 0.18 \\
\hline Carnitine $\dagger$ & 4.0 \\
\hline Picolinate $\dagger$ & 2.0 \\
\hline Ethanolamine $\dagger$ & 3.4 \\
\hline Taurine $\dagger$ & 15.0 \\
\hline Vitamin mix (dextrose $) \S$ & 500 \\
\hline Tricholine citrate $\dagger$ & 370 \\
\hline Cholesterol $\dagger$ & 40 \\
\hline
\end{tabular}

\begin{tabular}{lcc}
\hline \multicolumn{1}{c}{ Fat Sources } & $\mathrm{n}$-3 Def & $\mathrm{n}-3 \mathrm{Adq}$ \\
\hline & \multicolumn{2}{c}{$\mathrm{g} / 100 \mathrm{ml} \mathrm{milk}$} \\
MCT oild & 1.56 & 1.56 \\
Coconut oil (hydrogenated) & 3.24 & 3.24 \\
18:1n-9 ethyl ester** & 5.04 & 4.68 \\
18:2n-6 ethyl ester** & 2.16 & 2.16 \\
18:3n-3 ethyl ester** & - & 0.36 \\
\hline
\end{tabular}

Component sources were as follows: * NZMP (North America) Inc, Santa Rosa, CA; † Sigma-Aldrich Corp. St. Louis, MO; $\$$ Malinkrodt, Hazelwood, MO; § RX993666 Harlan, Madison, WI; II Mead Johnson Nutritionals, Evansville, IN; || Dyets, Bethlehem, PA; ** 99\% grade, Nu-Chek Prep, Inc. Elysian, MN.

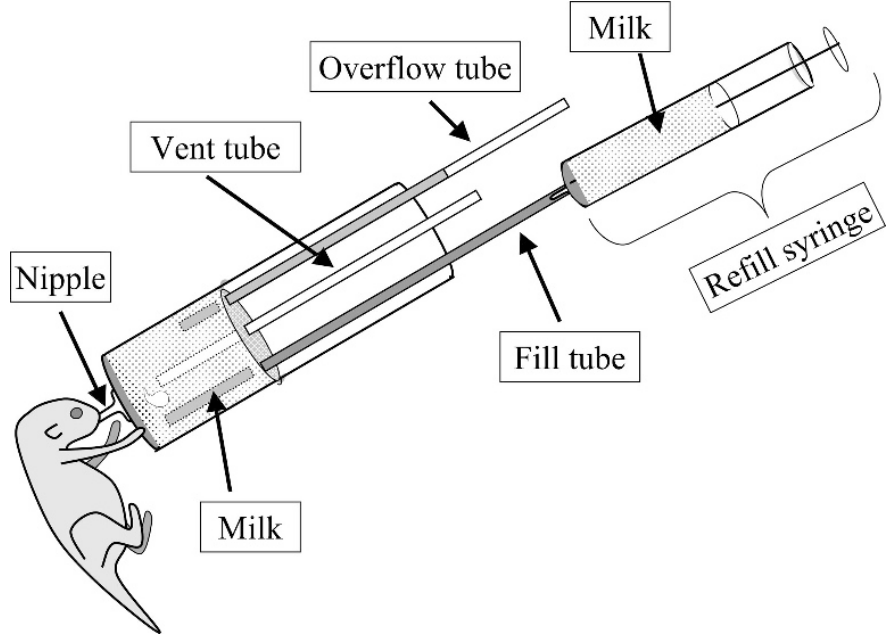

Figure 1. Feeding apparatus developed by Hoshiba (45).

$\mathrm{mL}$ aliquots in $50 \mathrm{~mL}$ conical tubes that were fitted with water-bottle tops so that rat pups could drink ad libitum. These pups were weaned to pelleted diets with a fat composition similar to that fed during the artificial rearing period (Table 1). The dam's milk group was weaned onto the same diet as their dams. When these artificially reared animals and dam-rearing animals were 8 wk old, behavioral experiments were begun.

Artificial rat milk. The artificial milk formula was modified from the method of Kanno et al. (46). Table 2 shows the ingredients used as well as their commercial sources. Casein and whey protein were used as protein sources and lactose was used as the carbohydrate. The protein sources were carefully chosen so as not to introduce significant levels of n-3 fatty acids, as this is often the major source of introduction of these components into n-3 fatty aciddeficient diets. Casein contained $2.9 \%$ methionine and whey protein contained $2.5 \%$ methionine. For complete dissolution, all ingredients were mixed in the order described by Kanno et al. so as to help prevent precipitation. The first step was that acid casein was slowly dissolved in an alkali solution with $\mathrm{NaOH}$ and $\mathrm{KOH}$ under continuous stirring at $70^{\circ} \mathrm{C}$. Three amino acids, serine, cystine, and tryptophan, were added to the alkali solution before the addition of casein as these protein sources contained lower levels of these amino acids relative to rat milk. In the second step, calcium and magnesium were added to the casein solution to obtain micelles of casein salts. A mixture of calcium and the calcium salt of glycerophosphoric acid $\left(\mathrm{GlyCaPO}_{4}\right)$, and $\mathrm{Mg}_{2} \mathrm{Cl}_{2}-6 \mathrm{H}_{2} \mathrm{O}$ in an appropriate amount of water, which had been autoclaved and then homogenized with a hand homogenizer (PGC Scientifics, Gaithersburg, MD), was slowly added to the casein solution with continuous stirring. Thereafter, the calcium citrate solution was slowly added (after autoclaving and homogenization). A lactose solution sterilized in an autoclave was added to the casein solution. A mixture of $\mathrm{Na}_{2} \mathrm{HPO}_{4}, \mathrm{KH}_{2} \mathrm{PO}_{4}, \mathrm{FeSO}_{4}, \mathrm{ZnSO}_{4}, \mathrm{CuSO}_{4}, \mathrm{MnSO}_{4}$, $\mathrm{NaF}$, and $\mathrm{KI}$ was added to the casein-micelle solution under continuous stirring. The casein salt solution was cooled to below $40^{\circ} \mathrm{C}$ and then whey protein in sterilized water was added to the solution with continuous stirring. A solution containing carnitine, picolinate, ethanolamine, taurine, tricholine citrate, the vitamin mixture, and $10 \mathrm{~N} \mathrm{NaOH}$ was then added. Finally, cholesterol and the fat sources were added to the above mixture under continuous stirring. The milk was then homogenized two times under high pressure (120 $\mathrm{kg} / \mathrm{cm}^{2}$ ), using a homogenizer with a two-stage valve (Model \#HP50-250 FES International, Irwindale, CA) that had been cleaned by rinsing with $0.1 \mathrm{M}$ $\mathrm{NaOH}$ and then neutralized with sterilized water. The homogenized milk was pasteurized twice at $63^{\circ} \mathrm{C}$ for $30 \mathrm{~min}, 6 \mathrm{~h}$ apart. The complete milk was poured into $500 \mathrm{~mL}$ sterilized bottles and stored at $4^{\circ} \mathrm{C}$. The final $\mathrm{pH}$ of milk was 6.5 . The milks contained $12 \mathrm{wt} \%$ lipids composed of saturated fat (medium chain triglycerides and hydrogenated coconut oil) and the ethyl ester form of purified unsaturated fatty acids (Nu-Chek Prep, Inc., Elysian, MN). The n-3 fatty acid deficient milk (n-3 Def) contained $16.3 \%$ LA and $0.02 \%$ LNA and the n-3 fatty acid adequate (n-3 Adq) milk contained $16.6 \%$ LA and 3.1\% LNA (Table 3). The addition of the LNA to the $\mathrm{n}-3$ Adq diet was substituted for an equal quantity of ethyl oleate; this introduced only a $7 \%$ difference in oleate content between the two diets. Saturated, monounsaturated, and LA were balanced with only the level of $18: 3 n-3$ as a dietary variable.

Pelleted diets. The three pelleted diets used were based on the AIN-93 (47) formulation with several modifications to obtain the extremely low n-3 fatty acid level required in this study (Table 1). The custom pelleted diets were obtained commercially and used a cold pelleting process to preserve unsatur- 
Table 3. Fatty acid compositions of artificial rat milk

\begin{tabular}{lcc}
\hline \multirow{2}{*}{ Fatty acids* } & \multicolumn{2}{c}{ Dietary group } \\
\cline { 2 - 3 } & $\mathrm{n}-3$ Def & $\mathrm{n}-3$ Adq \\
\hline Saturated & 33.8 & $\mathrm{~g} / 100 \mathrm{~g}$ \\
$\sum$ Monounsaturated & 48.4 & 32.6 \\
$18: 2 \mathrm{n}-6$ & 16.3 & 47.6 \\
$18: 3 \mathrm{n}-3$ & 0.02 & 16.6 \\
$\mathrm{n}-6 / \mathrm{n}-3$ & 815 & 3.1 \\
& & 5.5
\end{tabular}

* Only trace quantities of long the chain polyunsaturated fatty acids, $20: 4 n-6,20: 5 n-3,22: 5 n-3$ and $22: 6 n-3$ were detected, i.e. less than $0.01 \%$. Other minor peaks were not included.

ated fats (Dyets, Bethlehem, PA). The diets were designed to contain a fatty acid profile very similar to that in the artificial rat milk (or dam's milk) for each group. The dependent variable in the two artificially reared groups was the substitution of $\alpha$-linolenate ethyl ester for a portion of the oleate ethyl ester in the $\mathrm{n}-3$ Adq diet. The maternal diet contained a fatty acyl composition similar to that of the $\mathrm{n}-3$ Adq diet but was made up with a mixture of safflower and flax oils (rather than purified ethyl esters) due to the greater quantity of diet to be consumed. All three diets contained $10 \mathrm{wt} \%$ as fat and had a similar content of LA. The rats were maintained on the appropriate pelleted diet after weaning until they were killed.

Motor activity test. The motor activity of the animals was recorded using a video image analyzer (Videomax V, Columbus Instruments, Columbus, $\mathrm{OH}$ ). Each rat was individually placed at $0930-1300 \mathrm{~h}$ into a cage $(25 \mathrm{~cm} \times 45 \mathrm{~cm}$ $\times 20 \mathrm{~cm}$ ) and the moving time and the moving distance were measured for 30 min.

Elevated plus-maze. To order to measure anxiety-related behavior, the elevated plus-maze was used $(48,49)$. The plus maze was elevated $70 \mathrm{~cm}$ above the floor and consisted of two opposite open-arms $(45 \mathrm{~cm} \times 15 \mathrm{~cm})$ and two opposite enclosed-arms. The path of each animal was observed for $5 \mathrm{~min}$ after a resting period of $2 \mathrm{~min}$ in the central square of the maze. These measurements were repeated for $2 \mathrm{~d}$. The number of entries to the open arms and the visiting time of the open arm were recorded.

Morris water maze test. To evaluate performance in a spatial task, the Morris water maze test was performed. This method has been previously described in detail by Moriguchi et al. $(16,22)$. Briefly, the swimming area was arbitrarily divided into four quadrant (regions A-D), and two starting points were arranged at the corners of a quadrant rim. After swimming training, the rats were submitted to a visible trial where a black (visible) escape platform was placed in quadrant region A. If a rat failed to find the platform within $90 \mathrm{~s}$, it was gently placed on the platform for $30 \mathrm{~s}$. On the second day, a hidden platform was used in place of the black platform and each rat received two trials per day after being randomly placed at the two different starting points. The maximal trial length was $90 \mathrm{~s}$, with a maximal intertrial interval of 9 min. The escape latency was then defined as the sum of the two trials on a given day. The escape latency, swimming time, swimming speed, the duration of the floating state (resting time), and swimming path were automatically digitized and recorded by computer. Sessions were repeated for four consecutive days for a total of eight trials. On the day following the last session, the platform was removed and the rat was allowed to search for the platform for $90 \mathrm{~s}$ (probe trial). The number of crossings of the position where the platform had been placed (quadrant region $\mathrm{A}$ ) and the number of crossings in the corresponding imaginary positions in the other quadrant regions (regions B-D) were recorded.

Lipid composition. After the behavioral experiments at $15 \mathrm{wk}$ of age, the rats were killed by decapitation. Tissue samples including brain and retina were removed and stored at $-80^{\circ} \mathrm{C}$. The total lipid extracts of tissues were prepared according to the method of Folch et al. (50). The lipid extracts were transmethylated with $14 \% \mathrm{BF}_{3}$-methanol at $100^{\circ} \mathrm{C}$ for $60 \mathrm{~min}$ by a modification of the method of Morrison and Smith (51) with hexane addition (52). The total lipids in artificial milk and pelleted diets were extracted by the method of Lepage and Roy (53). Fatty acid methyl esters were then analyzed by gas chromatography as previously described (52). The fatty acid methyl esters were identified by comparison to the retention times of a standard mixture (Nu-Check Prep 462). The concentrations of individual and total fatty acids were obtained using an internal standard (22:3n-3 as methyl ester, 432 $\mu \mathrm{g} / \mathrm{brain}$ and $64.8 \mu \mathrm{g} /$ retina).

Statistical analysis. All data were expressed as mean \pm SEM and significance was determined using one-way ANOVA using Statistica (StatSoft, Tulsa, OK). Behavioral experiments were analyzed using Duncan's multiple range test when the initial repeated-measures ANOVA analyses resulted in significant differences. Body weight and fatty acid compositional differences were analyzed using Tukey's honest significant difference test.

\section{RESULTS}

Body weight. The artificially reared pups had a significantly lower body weight than that of dam reared pups from day 2 to 14 , but there were no significant differences between $n-3$ fatty acid deficient and $\mathrm{n}-3$ fatty acid adequate milk groups $[F(2,31)$ $=58.594, p<0.001$; n-3 Def, $p<0.001$; n-3 Adq, $p<0.001$ versus dam reared; $\mathrm{n}-3$ Def, $p=0.124$ versus $\mathrm{n}-3$ Adq (Fig. 2)]. After $15 \mathrm{~d}$ of age, the artificially reared pups gained weight rapidly so as to catch up to the dam-reared pups and there were no significant differences between the three dietary groups by $24 \mathrm{~d}$ of age. At $8 \mathrm{wk}$ old, at the beginning of the behavioral testing, the artificially reared rats showed significantly larger mean body weight than the dam reared group $[F(2,31)=$ 5.035, $p<0.05$; $\mathrm{n}-3$ Def, $p<0.05$; $\mathrm{n}-3$ Adq, $p<0.05$ versus dam reared; $\mathrm{n}-3$ Def, $p=0.992$ versus $\mathrm{n}-3$ Adq]. The mean body weights were $319 \pm 9 \mathrm{~g}$ for the n-3 Def milk group, 318 $\pm 8 \mathrm{~g}$ for the $\mathrm{n}-3$ Adq milk group, and $286 \pm 11 \mathrm{~g}$ for the dams' milk group. The only difference observed between damand artificially reared pups was the greater body weight from $\mathrm{d}$ 2 of age to d 14 of the dam-reared pups. There were no other differences apparent between dam- and artificially reared pups.

Brain and retinal fatty acid composition. The artificial rearing method was useful in obtaining low levels of brain and retina DHA in rats fed on the n-3 Def milk. The pelleted and artificial rat milk diets had very low n-3 fatty acids in the n-3 Def case with n-6/n-3 ratios of 297 (Table 1) and 815 (Table 3 ), respectively. The very high ratio was achieved in the latter case due to the use of purified fatty acid ethyl esters for the supply of the unsaturated fatty acids. This treatment was successful in inducing a loss in brain DHA. At 15 wk of age, rats in the n-3 Def group exhibited a 58\% and 60\% decrease in brain DHA compared with the n-3 Adq and dams' milk groups, respectively $[F(2,13)=286.000, p<0.001]$, which was

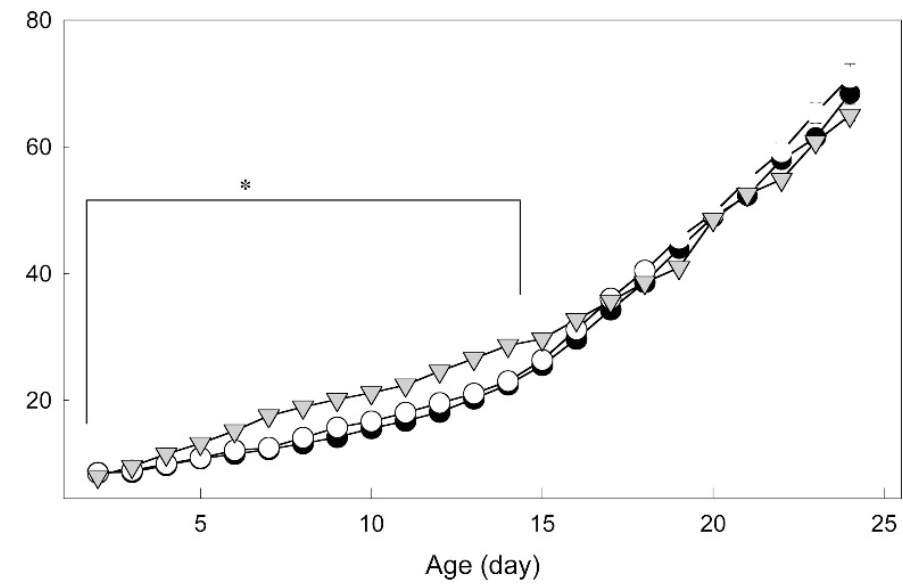

Figure 2. Body weights over the first $24 \mathrm{~d}$ of artificial rearing in comparison to dam-reared rat pups. The body weight is presented as the mean \pm SEM, with an $n=11$ or 12 . There were no significant differences between $\mathrm{n}-3$ fatty acid-deficient (black circle) and n-3 fatty acid-adequate milk (white circle) groups. $F(2,31)=58.594, p<0.001 ; \mathrm{n}-3$ Def, $p<0.001 ; \mathrm{n}-3$ Adq, $p<0.001$ $v s$ dam reared (inverted triangle); n-3 Def, $p=0.124 v s$ n-3 Adq. *indicates $p<0.001$ for Dam's group vs. the artifically reared groups fron $\mathrm{d} 2-\mathrm{d} 4$. 

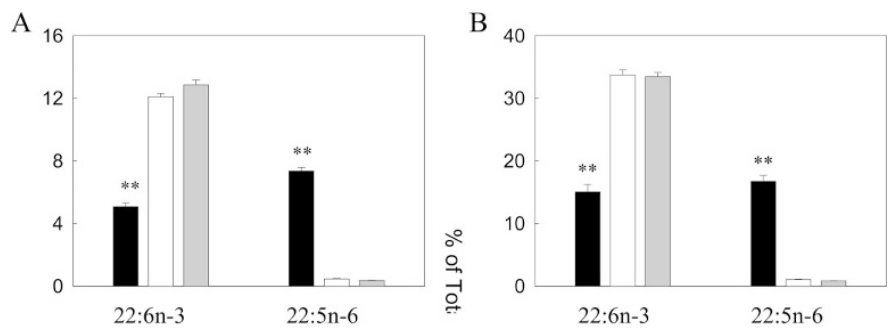

Figure 3. Effect of artificial rearing on an n-3 fatty acid-deficient or -adequate diet on $(A)$ brain and $(B)$ retina fatty acid composition $(n=13)$ at $15 \mathrm{wk}$ of age. The differences among the three groups in brain and retina fatty acid composition are significantly different in a one-way ANOVA $[F(2,13)=$ 286.000, $p<0.001$; n-3 Adq, $p<0.001$; dam's, $p<0.001 v s \mathrm{n}-3$ Def in brain DHA; $F(2,13)=966.536, p<0.001 ; \mathrm{n}-3$ Adq, $p<0.001$; dam's, $p<0.001$ vs n-3 Def in brain DPAn-6; $F(2,13)=134.012, p<0.001$; n-3 Adq, $p<$ 0.001 ; dam's, $p<0.001$ vs $\mathrm{n}-3$ Def in retina DHA; $F(2,13)=321.350, p<$ 0.001 ; n-3 Adq, $p<0.001$; dam's, $p<0.001$ vs n-3 Def in retina DPAn-6]. There was no significant difference between the n-3 Adq and dam's milk groups. ** Indicates $p<0.001$ for the n-3 Def vs. the n-3 Adq and Dam's

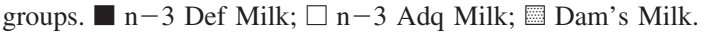

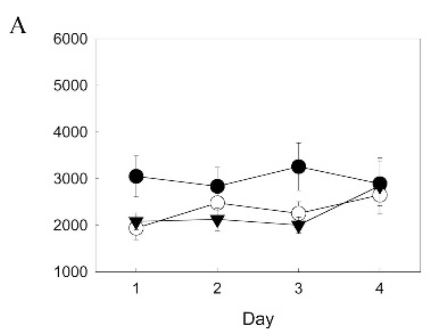

$F(2,32)=2.250, \mathrm{P}=0.122$

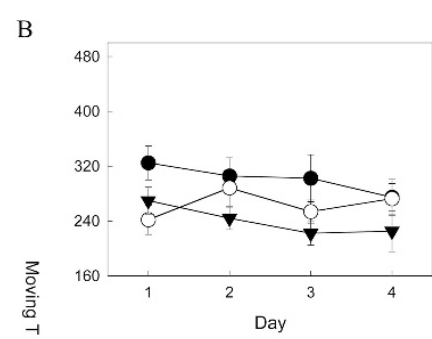

$F(2,32)=4.387, \mathrm{P}<0.05$ ; $\mathrm{n}-3$ Adq and n-3 Def vs. Dam's
Figure 4. Effect of n-3 fatty acid deficiency on $(A)$ moving distance and $(B)$ moving time in the motor activity test. The moving distance and moving time is presented as the mean \pm SEM, with $n=11$ or 12 . The differences among the three groups in the moving time are significantly different in a repeated measures, one-way ANOVA $[F(2,32)=4.387, p<0.05$; $\mathrm{n}-3$ Def, $p<0.01$ vs dam's]. $\longrightarrow$ n-3 Def Milk; —- $-\mathrm{n}-3$ Adq Milk; $\longrightarrow-$ Dam's Milk.

largely compensated for by a marked increase in brain DPAn-6 $[F(2,13)=966.536, p<0.001$ (Fig. 3) $]$. In addition, retinal DHA was decreased by $55 \%$ in the n-3-deficient group compared with both the n-3-adequate and dam-reared groups $[F(2,13)=134.012, p<0.001]$. The decrease was again largely replaced by an increased percentage of DPAn-6 $[F(2,13)=321.350, p<0.001]$.

Behavioral tests. In the motor activity test, there were no statistically significant differences in moving distance $[F(2,32)$ $=2.250, p=0.122]$ among the three groups (Fig. 4). However, the n-3 Def group showed a significantly greater moving time than the dam-reared group $[F(2,32)=4.387, p<0.05$; $\mathrm{n}-3$ Def, $p<0.01$ versus dam reared; Adq, $p=0.191$ versus dam reared].

In the elevated plus-maze test, the three groups showed significant differences between $\mathrm{d} 1$ and $\mathrm{d} 2$ in the visiting time in the open $\operatorname{arm}[F(1,28)=36.877, p<0.001]$ and number of visits to the open $\operatorname{arm}[F(1,28)=13.930, p<0.001$ (Fig. 5)]. However, there was no significant difference among the three groups in the visiting time to the open arm $[F(2,28)=1.885$, $p=0.171]$ and the number of visits to the open arm $[F(2,28)$ $=1.439, p=0.254$ (Fig. 5)].
A

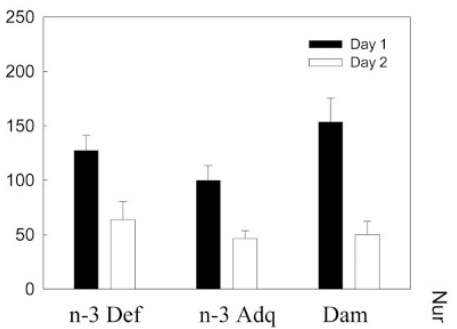

$\mathrm{B}$

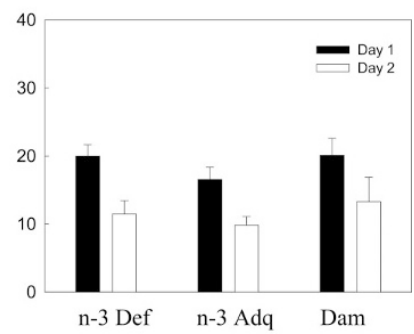

Figure 5. Effect of n-3 fatty acid deficiency on $(A)$ visiting time and $(B)$ number of visits in the open arm in the elevated plus maze. The visiting time and number of visits in the open arm is presented as the mean \pm SEM, with $n=10$ or 11 . The difference between days is significantly different in a repeated measures, one-way ANOVA $[F(1,28)=36.877, p<0.001$ for visiting time; $F(1,28)=13.930, p<0.001$ for number of visits].

In the Morris water maze test, the escape latency was not different among the dietary groups in the visible trial $[F(2,31)$ $=0.080, p=0.923$ (Table 4)]. In the visible trial, 3 rats out of 11 in the n-3 Def group reached the platform, whereas 5 of 12 in the n-3 Adq group and 5 out of 11 in the dam-reared group reached the platform. In the learning trials, the escape latency of the n-3 Adq and dams' milk groups gradually decreased over the testing period (Fig. 6). However, the n-3 Def rats showed a significantly longer escape latency than in either the n-3 Adq or the dams' milk group $[F(2,31)=4.546, p<0.05$; n-3 Adq, $p<0.05$; dam reared, $p<0.05$ versus n-3 Def]. There were no significant differences between the n-3 Adq and dams' milk groups.

The escape latency values were subdivided into swimming and resting time. The resting times in all groups were similar and there were no significant differences $[F(2,31)=1.184, p=$ 0.320] between the three groups (Fig. 7). Where the escape latency was increased in the n-3 Def group, the swimming time was also significantly increased $[F(2,31)=4.360, p<0.05$; n-3 Adq, $p<0.05$; dam reared, $p<0.05$ versus $\mathrm{n}-3$ Def (Fig. 7)] but again there was no difference between the n-3 Adq and dams' milk groups. During the learning trials, increases in swimming distance were associated with increased escape latency, and this difference was significant for the n-3 Def group in comparison to the other two dietary groups $[F(2,31)$ $=6.205, p<0.01$; n-3 Adq, $p<0.05$; dam reared, $p<0.01$ versus n-3 Def (Fig. 8)]. During the learning trials, the artificially reared rats displayed a significantly higher swimming speed compared with the dam-reared groups $[F(2,31)=4.927$, $p<0.05$; n-3 Def, $p<0.01$; n-3 Adq, $p<0.05$ versus dam reared (Fig. 8)].

In the memory retention trial, the number of crossings of the platform position (region A) was significantly greater than those of other regions for the n-3 Adq and dams' milk groups $[F(3,44)=6.021, p<0.005$ for $\mathrm{n}-3$ Adq milk; $F(3,40)=$ 9.390, $p<0.001$ for dams' milk (Fig. 9)]. However, the $n-3$ Def milk group swam randomly without preference for the previous platform location $[F(3,40)=1.594, p=0.206]$.

\section{DISCUSSION}

This study demonstrates that pups born to dams fed a relatively high LNA intake, an "n-3 adequate diet," during 
Table 4. Effect of n-3 fatty acid deficiency on the visible trial in the Morris water maze test

\begin{tabular}{lccc}
\hline \multicolumn{1}{c}{ Group } & No. of rats & Escape latency $(\mathrm{sec})$ & No. of successful rats \\
\hline n-3 Def & 11 & $74.2 \pm 8.8$ & 3 \\
n-3 Adq & 12 & $70.0 \pm 7.1$ & 5 \\
Dam's & 11 & $73.5 \pm 8.0$ & 5 \\
\hline
\end{tabular}

gestation can be made quite deficient in brain and retinal DHA by feeding a diet very low in n-3 fatty acids from the first days of life through adulthood. A first-generation model is presented that has more relevance to human nutrition than does the two-generational model that is most commonly used in this field. When the brain growth spurt (54) occurs in the absence of dietary n-3 fatty acids, the lack of DHA supply results in a marked loss of brain DHA. Recent studies have shown that most of the brain DHA is supplied by preformed DHA when available in the diet (55). In this study, biosynthesis from LNA is an insignificant source of brain DHA because it has been largely eliminated from the diet (Tables 1 and 3) and circulation (56). At adulthood ( 3 mo of age), the DHA is reciprocally replaced with the 22-carbon n-6 fatty acid, DPAn-6. However, it is now known that there is a lag in the replacement of the DHA by DPAn-6 in the first several weeks of life in the rat (57), apparently due to the limited rate of synthesis and transport of the DPAn-6 to neural membrane during very active neurogenesis.

The hand-feeding method used here employing the nursing bottles newly developed by Hoshiba (45) improves upon his previous systems $(43,44)$. In our hands, the mortality of pups has fallen dramatically with this new method as only 1 pup died out of 24 artificially reared in the present experiment. This pup died after aspirating milk into the lungs. There is also an

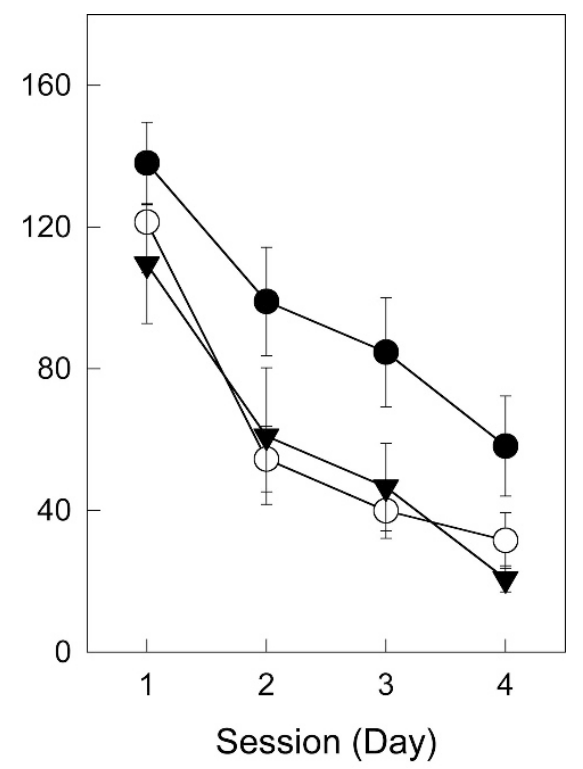

Figure 6. Effect of n-3 fatty acid deficiency on escape latency in the Morris water maze. The escape latency is presented as the mean \pm SEM, with $n=11$ or 12. The differences among three groups ("black circle symbol" n-3 Def Milk; "white circle" n-3 Adq Milk; "black inverted triangle" Dam's Milk) are significantly different in a repeated measures, one-way ANOVA $[F(2,31)=$ 4.546, $p<0.05$; n-3 Adq, $p<0.05$; dam's, $p<0.05$ vs n-3 Def]. $-\mathrm{n}-3$ Def Milk; - ——- n-3 Adq Milk; $\longrightarrow$ - Dam's Milk.

\section{A}

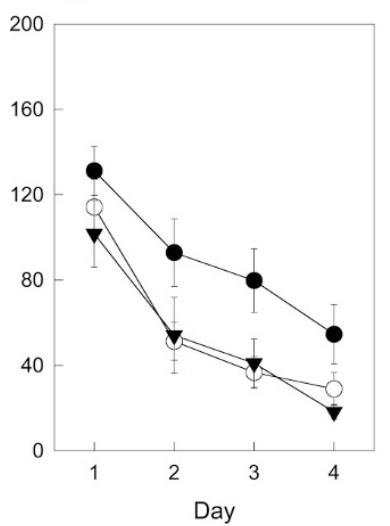

B

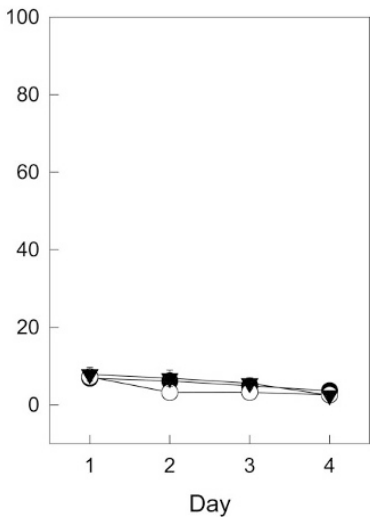

Figure 7. Fractional analysis of the escape latency in the Morris water maze. The swimming (A) and resting (B) times are presented as the mean \pm SEM, with $n=11$ or 12 . The differences in swimming time among the three groups ("black circle symbol" n-3 Def Milk; "white circle" n-3 Adq Milk; "black inverted triangle" Dam's Milk) are significantly different in a repeated measures, one-way ANOVA $[F(2,31)=4.360, p<0.05$; n-3 Adq, $p<0.05$; dam's, $p<0.05$ vs n-3 Def]. The resting time was not significantly different among the three different groups $[F(2,31)=1.184, p=0.320] . \longrightarrow \mathrm{n}-3$ Def Milk; - -

improvement in body weight growth with the AR pups catching up to their dam-reared siblings by about $\mathrm{d} 15$ and in adulthood exceeding the dam-reared body weight. From the latter observation, it appears that the AR procedure may have induced some difference in ad libitum feeding behavior. A decrease in stomach bloating was also noted with the present method, perhaps due to a decrease in the sucking in of air as the present system uses only the sucking power of the pup to regulate milk flow. Larger nipples are used that better fit the mouths of the pups. It should also be noted that this feeding system can be used to manipulate the intake of any dietary nutrient whose level can be controlled in the artificial rat milk.
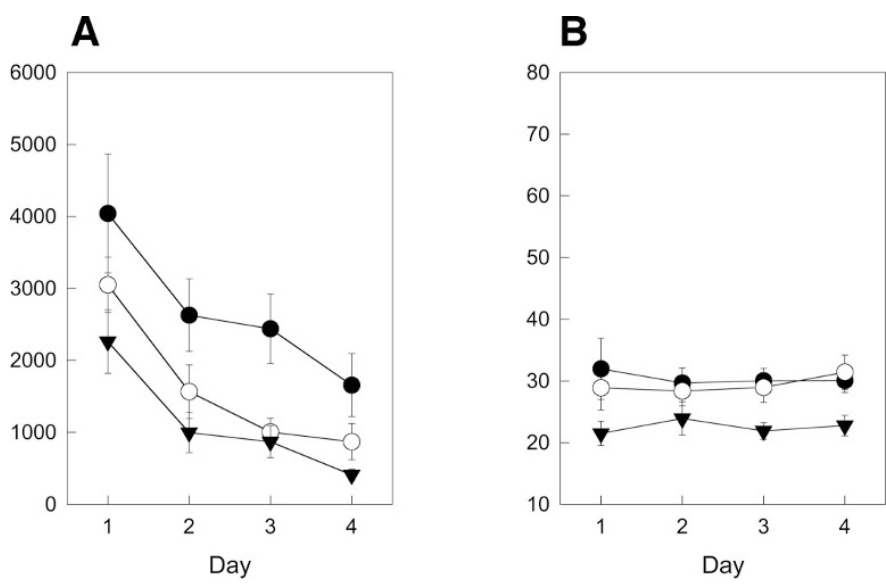

Figure 8. Effect of n-3 fatty acid deficiency on swimming distance and speed. The swimming distance (A) and speed (B) are presented as the mean \pm SEM, with $n=11$ or 12 . The differences in swimming distance among the three groups ("black circle symbol" n-3 Def Milk; "white circle" n-3 Adq Milk; "black inverted triangle" Dam's Milk) are significantly different in a repeated measures, one-way ANOVA $[F(2,31)=6.205, p<0.01$; n-3 Adq, $p<0.05$; dam's, $p<0.01 v s \mathrm{n}-3$ Def]. The swimming speed was significantly different among the three different groups $[F(2,31)=4.927, p<0.05$; n-3 Def, $p<$ 0.01; n-3 Adq, $p<0.05$ vs dam's]. - - n-3 Def Milk; - - $\bigcirc-$ n-3 Adq Milk; $\longrightarrow$ - Dam's Milk. 

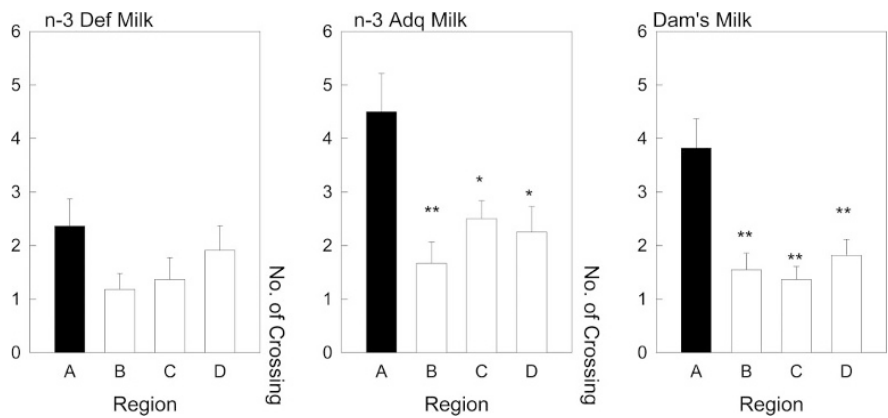

Figure 9. Effect of n-3 fatty acid deficiency on the probe trial. The number of crossings of the platform position (region A; closed column) and the corresponding imaginary positions (region B-D; open column) are presented as the mean \pm SEM, with $n=11$ or 12 . One-way ANOVA $[F(3,44)=6.021$, $p<0.005$ for $\mathrm{n}-3$ Adq milk; $F(3,40)=9.390, p<0.001$ for dam's milk]. $* p$ $<0.01,{ }^{*} p<0.001$ compared with region A (Duncan's multiple range test).

This study clearly demonstrates that the replacement of DHA with DPAn-6 leads to a loss in behavioral performance on spatial tasks. The escape latency and the spatial retention as assessed by the probe trial were impaired in the $n-3$ fatty acid-deficient rats whereas the rats fed an artificial rat milk containing LNA performed just as well as dam-reared rats. The behavioral performance correlated well with the DHA level in the brain as both the n-3 Adq and dam-reared groups had similar levels of brain DHA (12-13\% range) and low levels of DPAn-6 (about 0.4\%) whereas the n-3 Def group had only about 5\% brain DHA and about 7\% DPAn-6. In addition to the loss of DHA, the lag in replacement of DHA by DPAn-6 in early development (5-20 d postnatal) may also be a factor leading to losses in behavioral performance (57).

The mechanisms underlying loss of function in the n-3 fatty acid-deficient groups are not fully understood, but several lines of evidence now exist that can help to explain the critical role of DHA in the nervous system (1). It has been established that DHA positively modulates the biosynthesis and accumulation of phosphatidylserine in neuronal membranes $(58,59)$ and that this effect of DHA is closely related to signaling events supporting cell functions such as Raf-1 kinase translocation $(60,61)$. Kim et al. (60) also found that DHA enrichment prevents apoptotic cell death induced by serum starvation when an appropriate antioxidant is present. Apoptotic cell death plays an important role in neural development and its alteration as a result of DHA deficiency may have adverse consequences. Mitchell et al. (62) found that n-3 fatty acid deficiency led to desensitization in visual signaling as evaluated by rhodopsin activation, rhodopsin-G protein coupling, and integrated phosphodiesterase activity. Niu et al. (63) extended these findings to the in vivo situation with a demonstration of a loss in rhodopsin signaling in rod outer segment membranes prepared from n-3 Def or n-3 Adq animals. This effect of DHA on G-protein signaling system both in the retina and the brain could provide a general underlying mechanism for DHA function in the nervous system. Also, Katajka et al. (64) recently found that provision of $n-3$ polyunsaturated fatty acids altered brain gene expression including those involved in synaptic plasticity and learning, suggesting an independent mechanism for the beneficial effects of n-3 fatty acids on the nervous system.

In summary, this study suggested that feeding an n-3 fatty acid-deficient diet from postnatal d 2 through $15 \mathrm{wk}$ of age induced a 60\% reduction in brain DHA and produced a defect in spatial learning-related brain function. Compared with Asian countries, Western women's breast milk contains low levels of n-3 polyunsaturated fatty acids (65) and, until recently, Western milk formulas contained no long-chain (C20 or C22) polyunsaturates but essential fatty acids were supplied predominantly by vegetable oils rich in linoleic acid $(66,67)$. It is clear that the fatty acid composition of infant brain and retina is influenced by the mother's dietary habits and that infants who receive vegetable oil-based formulas have a decrease in brain DHA $(68,69)$. Whether the more moderate $n-3$ fatty acid deficiencies in the adult human population would lead to a loss in brain DHA is as yet unclear.

\section{REFERENCES}

1. Salem N Jr, Litman B, Kim HY, Gawrisch K 2001 Mechanisms of action of docosahexaenoic acid in the nervous system. Lipids 36:945-959

2. Innis SM 1991 Essential fatty acids in growth and development. Prog Lipid Res 30:39-103

3. Neuringer M, Anderson GJ, Connor WE 1988 The essentiality of n-3 fatty acids for the development and function of the retina and brain. Annu Rev Nutr 8:517-541

4. Okuyama H, Kobayashi T, Watanabe S 1996 Dietary fatty acids-the N-6/N-3 balance and chronic elderly diseases. Excess linoleic acid and relative N-3 deficiency syndrome seen in Japan. Prog Lipid Res 35:409-457

5. Tinoco J, Babcock R, Hincenbergs I, Medwadowski B, Miljanich P, Williams MA 1979 Linolenic acid deficiency. Lipids 14:166-173

6. Yamamoto N, Hashimoto A, Takemoto Y, Okuyama H, Nomura M, Kitajima R, Togashi T, Tamai Y 1988 Effect of the dietary alpha-linolenate/linoleate balance on lipid compositions and learning ability of rats. II. Discrimination process, extinction process, and glycolipid compositions. J Lipid Res 29:1013-1021

7. Bourre JM, Francois M, Youyou A, Dumont O, Piciotti M, Pascal G, Durand G 1989 The effects of dietary alpha-linolenic acid on the composition of nerve membranes, enzymatic activity, amplitude of electrophysiological parameters, resistance to poisons and performance of learning tasks in rats. J Nutr 119:1880-1892

8. Nakashima Y, Yuasa S, Hukamizu Y, Okuyama H, Ohhara T, Kameyama T, Nabeshima T 1993 Effect of a high linoleate and a high alpha-linolenate diet on general behavior and drug sensitivity in mice. J Lipid Res 34:239-247

9. Benolken RM, Anderson RE, Wheeler TG 1973 Membrane fatty acids associated with the electrical response in visual excitation. Science 182:1253-1254

10. Neuringer M, Connor WE, Lin DS, Barstad L, Luck S 1986 Biochemical and functional effects of prenatal and postnatal omega 3 fatty acid deficiency on retina and brain in rhesus monkeys. Proc Natl Acad Sci U S A 83:4021-4025

11. Weisinger HS, Vingrys AJ, Sinclair AJ 1996 Effect of dietary n-3 deficiency on the electroretinogram in the guinea pig. Ann Nutr Metab 40:91-98

12. Jeffrey BG, Mitchell DC, Hibbeln JR, Gibson RA, Chedester AL, Salem N Jr 2002 Visual acuity and retinal function in infant monkeys fed long-chain PUFA. Lipids 37:839-848

13. Pawlosky RJ, Denkins Y, Ward G, Salem N Jr 1997 Retinal and brain accretion of long-chain polyunsaturated fatty acids in developing felines: the effects of corn oil-based maternal diets. Am J Clin Nutr 65:465-472

14. Wainwright PE, Huang YS, Bulman-Fleming B, Mills DE, Redden P, McCutcheon D 1991 The role of n-3 essential fatty acids in brain and behavioral development: a cross-fostering study in the mouse. Lipids 26:37-45

15. Frances H, Coudereau JP, Sandouk P, Clement M, Monier C, Bourre JM 1996 Influence of a dietary alpha-linolenic acid deficiency on learning in the Morris water maze and on the effects of morphine. Eur J Pharmacol 298:217-225

16. Moriguchi T, Greiner RS, Salem N Jr 2000 Behavioral deficits associated with dietary induction of decreased brain docosahexaenoic acid concentration. J Neurochem 75:2563-2573

17. Greiner RS, Moriguchi T, Hutton A, Slotnick BM, Salem N Jr 1999 Rats with low levels of brain docosahexaenoic acid show impaired performance in olfactory-based and spatial learning tasks. Lipids 34(suppl):S239-S243

18. Greiner RS, Moriguchi T, Slotnick BM, Hutton A, Salem N Jr 2001 Olfactory discrimination deficits in n-3 fatty acid-deficient rats. Physiol Behav 72:379-385

19. Catalan J, Moriguchi T, Slotnick B, Murthy M, Greiner RS, Salem N Jr 2002 Cognitive deficits in docosahexaenoic acid-deficient rats. Behav Neurosci 116:1022-1031

20. Neuringer M, Connor WE, Van Petten C, Barstad L 1984 Dietary omega-3 fatty acid deficiency and visual loss in infant rhesus monkeys. J Clin Invest 73:272-276

21. Champoux M, Hibbeln JR, Shannon C, Majchrzak S, Suomi SJ, Salem N Jr., Higley JD 2002 Fatty acid formula supplementation and neuromotor development in rhesus monkey neonates. Pediatr Res 51:273-281 
22. Moriguchi T, Salem N Jr 2003 Recovery of brain docosahexaenoate leads to recovery of spatial task performance. J Neurochem 87:297-309

23. Weisinger HS, Vingrys AJ, Bui BV, Sinclair AJ 1999 Effects of dietary n-3 fatty acid deficiency and repletion in the guinea pig retina. Invest Ophthalmol Vis Sci 40:327-338

24. Carrie I, Clement M, de Javel D, Frances H, Bourre JM 2000 Phospholipid supplementation reverses behavioral and biochemical alterations induced by $n-3$ polyunsaturated fatty acid deficiency in mice. J Lipid Res 41:473-480

25. Ikemoto A, Ohishi M, Sato Y, Hata N, Misawa Y, Fujii Y, Okuyama H 200 Reversibility of n-3 fatty acid deficiency-induced alterations of learning behavior in the rat: level of n-6 fatty acids as another critical factor. J Lipid Res 42:1655-1663

26. Kodas E, Vancassel S, Lejeune B, Guilloteau D, Chalon S 2002 Reversibility of n-3 fatty acid deficiency-induced changes in dopaminergic neurotransmission in rats: critical role of developmental stage. J Lipid Res 43:1209-1219

27. Lewis NM, Widga AC, Buck JS, Frederick AM 1995 Survey of omega-3 fatty acids in diets of midwest low-income pregnant women. J Agromed 2:49-57

28. Innis SM, Elias SL 2003 Intakes of essential n-6 and n-3 polyunsaturated fatty acids among pregnant Canadian women. Am J Clin Nutr 77:473-478

29. Kris-Etherton PM, Taylor DS, Yu-Poth S, Huth P, Moriarty K, Fishell V, Hargrove RL, Zhao G, Etherton TD 2000 Polyunsaturated fatty acids in the food chain in the United States. Am J Clin Nutr 71:179S-188S

30. Lands WE, Hamazaki T, Yamazaki K, Okuyama H, Sakai K, Goto Y, Hubbard VS 1990 Changing dietary patterns. Am J Clin Nutr 51:991-993

31. Iso H, Sato S, Folsom AR, Shimamoto T, Terao A, Munger RG, Kitamura A, Konishi M, Iida M, Komachi Y 1989 Serum fatty acids and fish intake in rural Japanese, urban Japanese, Japanese American and Caucasian American men. Int J Epidemiol 18:374381

32. Pawlosky RJ, Hibbeln JR, Novotny JA, Salem N Jr 2001 Physiological compartmental analysis of alpha-linolenic acid metabolism in adult humans. J Lipid Res 42:12571265

33. Woods J, Ward G, Salem N Jr 1996 Is docosahexaenoic acid necessary in infant formula? Evaluation of high linolenate diets in the neonatal rat. Pediatr Res 40:687694

34. Bourre JM, Dumont O, Pascal G, Durand G 1993 Dietary alpha-linolenic acid at 1.3 $\mathrm{g} / \mathrm{kg}$ maintains maximal docosahexaenoic acid concentration in brain, heart and liver of adult rats. J Nutr 123:1313-1319

35. Abedin L, Lien EL, Vingrys AJ, Sinclair AJ 1999 The effects of dietary alphalinolenic acid compared with docosahexaenoic acid on brain, retina, liver, and heart in the guinea pig. Lipids 34:475-482

36. Bowena RA, Clandinin MT 2000 High dietary 18:3n-3 increases the 18:3n-3 but not the $22: 6 n-3$ content in the whole body, brain, skin, epididymal fat pads, and muscles of suckling rat pups. Lipids 35:389-394

37. Hibbeln JR, Salem N Jr 2001 Omega-3 fatty acids and psychiatric disorders. In: Mostofsky DI, Yehuda S, Salem N Jr (eds) Fatty Acids: Physiological and Behavioral Functions. Humana Press, Totowa, NJ, pp 3-22

38. Peet M, Horrobin DF 2002 A dose-ranging study of the effects of ethyleicosapentaenoate in patients with ongoing depression despite apparently adequate treatment with standard drugs. Arch Gen Psychiatry 59:913-919

39. Hibbeln JR, Makino KK 2001 Omega-3 fats in depressive disorders and violence: the context of evolution and cardiovascular health. In: Skinner ER (ed) Brain Lipids and Disorders in Biological Psychiatry. Elsevier Science BV, New York, pp 67-110

40. Weisinger HS, Armitage JA, Jeffrey BG, Mitchell DC, Moriguchi T, Sinclair AJ, Weisinger RS, Salem N Jr 2002 Retinal sensitivity loss in third-generation n-3 PUFA-deficient rats. Lipids 37:759-765

41. Moriguchi T, Lim SY, Greiner R, Lefkowitz W, Loewke J, Hoshiba J, Salem N Jr 2004 Effects of an n-3-deficient diet on brain, retina, and liver fatty acyl composition in artificially reared rats. J Lipid Res 45:1437-1445

42. Lim SY, Moriguchi T, Lefkowitz B, Loewke J, Majchrzak S, Hoshiba J, Salem N Jr 2003 Artificial feeding of an n-3 essential fatty acid deficient diet leads to a loss of brain function in the first generation. In Yung-Sheng H., Shing-Jong L, Po-Chao H (eds): Essential Fatty Acids and Eicosanoids. AOCS Press, Champain, IL pp 122-131

43. Hoshiba J 1986 An automatic feeder for infant rats. Lab Anim Sci 36:682-685

44. Hoshiba J 1996 Automatic feeder for newborn rat use within 12 hours of birth Contemp Top Lab Anim Sci 35:83-86
45. Hoshiba J 2004 Method for hand-feeding mouse pups with nursing bottles. Contemp Top Lab Anim Sci 43:50-53

46. Kanno T, Koyanagi N, Katoku Y, Yonekubo A, Yajima T, Kuwata T, Kitagawa H, Harada E 1997 Simplified preparation of a refined milk formula comparable to rat's milk: influence of the formula on development of the gut and brain in artificially reared rat pups. J Pediatr Gastroenterol Nutr 24:242-252

47. Reeves PG, Nielsen FH, Fahey GC Jr 1993 AIN-93 purified diets for laboratory rodents: final report of the American Institute of Nutrition ad hoc writing committee on the reformulation of the AIN-76A rodent diet. J Nutr 123:1939-1951

48. File SE, Zangrossi H Jr, Viana M, Graeff FG 1993 Trial 2 in the elevated plus-maze: a different form of fear? Psychopharmacology (Berl) 111:491-494

49. File SE, Gonzalez LE 1996 Anxiolytic effects in the plus-maze of 5-HT1A-receptor ligands in dorsal raphe and ventral hippocampus. Pharmacol Biochem Behav 54:123-128

50. Folch J, Lees M, Sloane Stanley GH 1957 A simple method for the isolation and purification of total lipids from animal tissues. J Biol Chem 226:497-509

51. Morrison WR, Smith LM 1964 Preparation of fatty acid methyl esters and dimethylacetals from lipids with boron fluoride-methanol. J Lipid Res 53:600-608

52. Salem N Jr., Reyzer M, Karanian J 1996 Losses of arachidonic acid in rat liver after alcohol inhalation. Lipids 31(suppl):S153-S156

53. Lepage G, Roy CC 1986 Direct transesterification of all classes of lipids in a one-step reaction. J Lipid Res 27:114-120

54. Schiefermeier M, Yavin E 2002 n-3 Deficient and docosahexaenoic acid-enriched diets during critical periods of the developing prenatal rat brain. J Lipid Res 43:124-131

55. Lefkowitz W, Lim SY, Lin Y, Salem N Jr 2005 Where does the developing brain obtain its docosahexaenoic acid? Relative contributions of dietary alpha-linolenic acid, docosahexaenoic acid, and body stores in the developing rat. Pediatr Res 57:157-165

56. Moriguchi T, Loewke J, Garrison M, Catalan JN, Salem N Jr 2001 Reversal of docosahexaenoic acid deficiency in the rat brain, retina, liver, and serum. J Lipid Res 42:419-427

57. Greiner RS, Catalan JN, Moriguchi T, Salem N Jr 2003 Docosapentaenoic acid does not completely replace DHA in n-3 FA-deficient rats during early development Lipids 38:431-435

58. Hamilton L, Greiner R, Salem N Jr., Kim HY 2000 n-3 fatty acid deficiency decreases phosphatidylserine accumulation selectively in neuronal tissues. Lipids 35:863-869

59. Kim HY, Bigelow J, Kevala JH 2004 Substrate preference in phosphatidylserine biosynthesis for docosahexaenoic acid containing species. Biochemistry 43:10301036

60. Kim HY, Akbar M, Lau A, Edsall L 2000 Inhibition of neuronal apoptosis by docosahexaenoic acid (22:6n-3). Role of phosphatidylserine in antiapoptotic effect. J Biol Chem 275:35215-35223

61. Akbar M, Kim HY 2002 Protective effects of docosahexaenoic acid in staurosporineinduced apoptosis: involvement of phosphatidylinositol-3 kinase pathway. J Neurochem 82:655-665

62. Mitchell DC, Niu SL, Litman BJ 2003 DHA-rich phospholipids optimize G-Proteincoupled signaling. J Pediatr 143:S80-S86

63. Niu SL, Mitchell DC, Lim SY, Wen ZM, Kim HY, Salem N Jr., Litman BJ 2004 Reduced $\mathrm{G}$ protein-coupled signaling efficiency in retinal rod outer segments in response to n-3 fatty acid deficiency. J Biol Chem 279:31098-31104

64. Kitajka K, Sinclair AJ, Weisinger RS, Weisinger HS, Mathai M, Jayasooriya AP, Halver JE, Puskas LG 2004 Effects of dietary omega-3 polyunsaturated fatty acids on brain gene expression. Proc Natl Acad Sci U S A 101:10931-10936

65. Jensen RG 1999 Lipids in human milk. Lipids 34:1243-1271

66. Nettleton JA 1991 Omega-3 fatty acids: comparison of plant and seafood sources in human nutrition. J Am Diet Assoc 91:331-337

67. Raper NR, Cronin FJ, Exler J 1992 Omega-3 fatty acid content of the US food supply. J Am Coll Nutr 11:304-308

68. Farquharson J, Cockburn F, Patrick WA, Jamieson EC, Logan RW 1992 Infant cerebral cortex phospholipid fatty-acid composition and diet. Lancet 340:810-813

69. Makrides M, Neumann MA, Byard RW, Simmer K, Gibson RA 1994 Fatty acid composition of brain, retina, and erythrocytes in breast- and formula-fed infants. Am J Clin Nutr 60:189-194 